\title{
XXVI SICOT Triennial World Congress and the forty sixth SBOT Annual Meeting
}

\author{
Maurice Hinsenkamp
}

Received: 28 May 2014 / Accepted: 2 June 2014 / Published online: 26 June 2014

(C) SICOT aisbl 2014

This year, the association of the SICOT Triennial World Congress with the Sociedade Brasileira de Ortopedia e Traumatologia (SBOT) meeting will offer you a giant-sized congress. Thirty-three years after the first SICOT meeting in Rio de Janeiro in 1981, our Society returns to this gorgeous city.

The Scientific Committees of SICOT and SBOT have prepared for you, with even greater attention, an exceptional scientific programme.

During the four-day meeting, 16 sessions will run in parallel. The most exciting topics have simultaneous translation while the other rooms are divided between the English and Portuguese languages. This will allow you to discover more deeply the work of our colleagues from Latin America.

The two plenary speakers are Andrew Carr who will talk about "Improving Evidence in Orthopaedic Surgery: A Global Challenge" and John Dormans who will speak about "Children's Trauma: A Global Perspective".

The SICOT sessions include 66 Free Paper Sessions allowing a maximum of oral presentations from orthopaedic surgeons from around the world, 46 Symposia exhaustively exploring hot current topics, ten Instructional Courses satisfying our young and also less young colleagues, and 16 Focused Poster Sessions.

This year, the Educational Day is on the shoulder and elbow. Experts from over ten countries will participate with the objective of providing a comprehensive review course for residents and an evidence-based update for practising surgeons.

Among the Symposia, the main topics will be explored, such as bone infection, computer-assisted surgery, hip

\section{Hinsenkamp $(\triangle)$}

Department of Orthopaedic Surgery, Hôpital Erasme, Université

Libre de Bruxelles ULB, Route de Lennik 808, Brussels 1070,

Belgium

e-mail: mhinsenk@ulb.ac.be

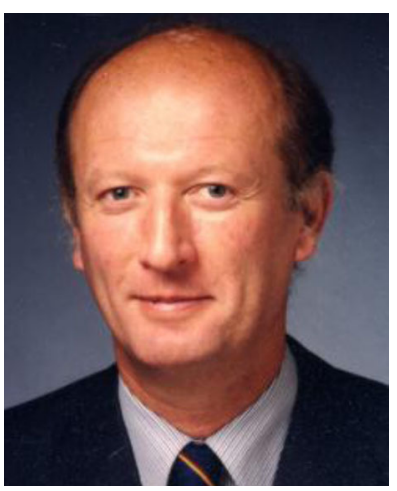

arthroscopy, microsurgery, as well as research including breakthroughs in tissue engineering, surgical safety for orthopaedic patients, and the current subspecialty topics on hand, hip, knee, spine, and sports medicine.

This year, our Trauma Committee concentrates its interest not only on fractures of the proximal humerus and elbow, but also on polytrauma and acetabular fractures.

After the great success last year, we will have a special symposium organised by our Editors of International Orthopaedics on "How to write and publish a paper".

The SICOT Young Surgeons Committee has prepared two new Symposia on "Malpractice Claims in Orthopaedic Surgery" and "Leadership and Management".

Our annual symposium on Natural Disasters will focus this year on the prerequisites, following the previous symposia on amputation [1], triage [2] and external fixation [3] in the last three years. The objective of this symposium is to specify the training, equipment and infrastructure needed for humanitarian missions.

Specialised Symposia are also organised by subspecialty societies such as AO Spine and Trauma, ARTOF (Association for Rational Treatment of Fractures), ASAMI (Association for 
the Study and Application of the Method of Ilizarov), Clubfoot Society, IFPOS (International Federation of Paediatric Orthopaedic Societies), IHS (International Hip Society), ISMST (International Society for Medical Shockwave Treatment), SRS (Scoliosis Research Society), and WOC (World Orthopaedic Concern). This year, a SLAOT (Latin American Society of Orthopaedics and Traumatology) Symposium is organised on controversies in hip trauma and the annual Symposium of SOFCOT (French Society of Orthopaedic Surgery and Traumatology) will be on distal fractures of the femur.

In parallel, SBOT has prepared a complete programme highlighting the most current topics in Orthopaedics and Trauma. The President of the SBOT is Arnaldo Hernandez and its Congress President Geraldo Motta. The SICOT Congress President is Jose Sergio Franco. The devoted teams of both SICOT and SBOT worked hard to make a memorable experience from this congress not only by scientific exchange but also by the exploration of the rich local culture with an exceptional exceptional ambiance of samba and bossa nova ambiance.

Among other SICOT news, we are happy to report that International Orthopaedics has now reached an Impact Factor of 2.319 and offers you more than ever a well-recognised international forum for your work, which complements the opportunity offered by our congress.

This year SICOT was present at the World Health Assembly and at the World Health Organization Executive
Board meeting in Geneva. We "strongly support that surgical care must be part of primary care and it needs to be integrated into the national health plans of all countries. The need to strengthen surgical capacity, particularly at the district level, is cost-efficient in our efforts in reducing the global burden of surgical disease".

Following this statement, the resolution below will be unanimously proposed at the 68th WHA in 2015: "Strengthening Emergency and Essential Surgical Care and Anaesthesia as a component of Universal Health Coverage". This will be an important step in promoting Orthopaedic Surgery and Traumatology among the priority disciplines to be supported in clinics and research.

Be there where things are happening and do not miss the SICOT meeting in Rio de Janeiro!

Maurice Hinsenkamp

SICOT President

\section{References}

1. Hinsenkamp M (2012) SICOT contribution to natural disasters assistance. Int Orthop 36(10):1977-1978

2. Hinsenkamp M (2013) SICOT contribution to natural disaster assistance: the triage. Int Orthop 37(8):1427-1428

3. Hinsenkamp M (2014) SICOT contribution to natural disaster assistance: the external fixator. Int Orthop 38(8) 